\title{
http://bjas.journals.ekb.eg
}

\section{Functional Endoscopic Sinus Surgery in Paediatrics Meta analysis Study}

\author{
k.A.abdeljalil, M.A.Elsisi and N.S.Kazem
}

Otorhinolaryngology Dept., Faculty of Medicine, Benha Univ., Benha, Egypt

E-Mail:kamal2356@gmail.com

\begin{abstract}
Systematically review the published outcome measures for treatment of chronic rhinosinusitis in the pediatric group of patients to find out the evidence for the efficacy of function endoscopic sinus surgery in management of PCRS. A metaanalysis of the writing ahead results from claiming pediatric fess An meta-analysis of the written works might have been performed centering on the amount about patients for every study, length from claiming follow-up, prospective versus retrospective, and the division or avoidance of patients with noteworthy underlying systemic sicknesses (cystic fibrosis Also immunodeficiencies). An rating scale In light of the over criteria might have been used to select articles for consideration. The incorporated 15 articles were efficiently investigated. Around these incorporated articles , 9 articles required pediatrics patients underwent endoscopic sinus surgery What's more 6 articles underwent adenoidectomy to medication of CRS Previously, pediatrics. Each of the incorporated investigations might have been doled out An level from claiming confirmation What's more agrade for suggestion. Our study news person that pediatric fess will be an viable medicine to unending rhinosinusitis; for triumph rate over $87 \%$. Pediatric fess is An sheltered Furthermore successful medication for Ceaseless sinusitis that is recalcitrant will therapeutic help.
\end{abstract}

Keywords :Pediatric, Chronic sinusitis, Treatment, FESS, Meta-analysis .

\section{Introduction}

Constant rhinosinsuitis to Youngsters could make characterized Concerning illustration a incendiary transform directing, including those paranasal sinuses to in any event 3 months. It will be An fundamental reason for horribleness in the pediatric populace. Despite it may be was troublesome will assess the occurrence of incessant rhinosinusitis in children, $5-10 \%$ for pediatric number for upper respiratory tract contamination will try around should create intense rhinosinsuitis, with an aggregation for them Advance ahead to incessant ailment [1].

Rhinosinusitis may be a as a relatable point illness watched On children; though, there would a number hypotheses as respect to its pathogenesis and administration. Regular reasons include; upper respiratory tract infection, hypersensitive rhinitis, block of the osteomeatal mind boggling (OMC), and mucociliary brokenness [2].

Those etiology about intense alternately constant sinusitis is block of the outpouring tracts of the tolerant sinuses, generally Likewise aresult about mucosal edema. Those Head outpouring tract of the sinuses, particularly those foremost one assembly (most usually affected), may be through those ostiomeatal intricate close to the ethmoid pit What's more working turbinate. Mucosal edema might be expected with concoction or natural irritants [3].

Extended adenoid camwood cause direct to extreme nasal hindrance. Those adenoid couch need also been expected will a chance to be An supply to bacterial infections of the sinuses Also center ear. Takahashi et al. , discovered that there will be change clinched alongside sinusitis manifestations and clinical endoscopic picture after six months Previously, 55\% of kids underwent adenoidectomy, versus $25 \%$ clinched alongside kids who didn't experience adenoidectomy [4].

Rhinosinusitis is the favored term with portray pediatrics with persistency nasal manifestations for confirmation of contaminated sinus once paranasl sinus figured tomography (CT) filters. Rhinosinusitis
Previously, pediatrcs will be viewed as Similarly as intense (2-4 weeks), subacute (2-4 weeks to 2-3 months) alternately unending (more over 2-3 months) [5].

Difficulties for unending Furthermore repetitive intense rhinosinusitis would not common, Be that over know youngsters they bring not kidding issues due to the dainty boney dividers of the sinuses Furthermore of the features of development of the sinuses that finishes around the period of 12 years. In any case the horribleness and mortal sin about Pediatrc CRS stay high, In this way huge exertion from the doctor may be important for initial identification [6].

Imaging could a chance to be precise valuable On selecting which cases require surgery, coronal What's more pivotal cuts for ct examine of the sinuses will be prescribed with assess At whatever tolerant with suspected muddling [6].

A large portion of patients demonstrate agood light of medicinal medicine with antibiotics; however, surgical mediation will be recognized to repetitive cases not reacting on prolonged restorative management [7].

Elective on oral anti-microbial help, utilitarian endoscopic sinus surgery (FESS) Also adenoidectomy are sensible intercessions. Despite pediatric fess may be generally utilized for those medicine from claiming recalcitrant CRS situations for achievement rates 80$90 \%$, apprehensions exist again conceivable obstruction for facial skeletal Growth What's more further adhesions of the waste pathway. Adenoidectomy both opens nasal aviation route Also removes those reservoire for unending bacterial spoiling [8].

Fess is lesquerella obtrusive surgical method that opens up those paranasal sinus ostia. It need two fundamental objectives: which are greatest protection of the sinuses mucosa Also securing correspondence the middle of those nasal hole and the paranasal sinuses through those common pathways [9].

Since 1989, fess need quickly picked up acknowledgement Concerning illustration the essential surgical methodology to those medication of constant sinusitis in the pediatric age class. In spite of fess in kids 
need aid comparable to the individuals clinched alongside adults, pediatric fess may be accepted will be more troublesome due to littler paranasal sinuses examine to Youngsters [12].

\section{Materials and methods}

This study was done in the following steps:

1. Determination of the target disease.

2. Identification and location of articles.

3. Screening and evaluation of articles.

4. Data collection.

5. Data analysis.

6. Reporting and interpretation.

7. Discussion and conclusions. 8.

\section{1) Target}

Application of functional endoscopic sinusis surgery (FESS) in pediatric population (effective or not).

\section{2) Identification and location of articles}

Published medical articles regarding chronic rhinosinusitis treatment in children in pubmed database (medscape medline) till 2016 in the last 28 years , using the following keywords

- Treatment of chronic rhinosinusitis in children.

- Pediatric chronic rhinosinusitis

- Functional endoscopic sinus surgery in children

- Adenoidectomy for chronic rhinosinusitis in children.

- Surgical treatment of chronic rhinosinusitis in children.

\section{3) Screening and evaluation}

Articles incorporated were screened should report card for cases in regards to comprehensive What's more select criteria:. Incorporation criteria:. - randomized regulated clinical Trials, controlled clinical trial, the event series\& companion.

- Youngsters age-old 2-16 A long time with finding for unending rhinosinusitis Similarly as characterized by the vicinity of thick nasal release or/and blockage Also profitable hack for An base from claiming 3 months.

- ct examine indicating abnormal mucosal thickening alternately opacification or air liquid level for you quit offering on that one alternately both sinus antra.
- Patients ought to make emulated up following those operation in any event three months.

\section{Exclusion criteria}

- Review articles and case series articles including less than six patients.

- Patients with immunodeficiency syndromes and drug allergy will be excluded.

- Patients with evidence of haematological, renal, hepatic or cardiovascular disorders.

\section{4) Data collection}

Those information were gathered from those decided articles satisfying the formerly specified criteria. The greater part of the papers utilized questionnaires sent with guardians.

\section{5) Data analysis}

Data analysis was performed utilizing Review Manager (RevMan) [Computer program]. Version 5.0 Copenhagen.

\section{6) Reporting and interpretation of the results}

This was performed by the above mentioned Metaanalytical soft ware, Review Manager (Rev-Man 5) .

\section{7)Discussion and conclusion.}

\section{Results}

The look brought about 339 articles out of them 183 might have been important of the target, Eventually Tom's perusing evacuating repeater articles (41 articles); the aggregate important articles need aid 142 table (1).

Know searches yielded 142 pertinent articles, for which best 15 articles were incorporated table( 2$)$. Around these included articles , 9 articles needed pediatrics patients underwent endoscopic sinus surgery What's more 6 articles underwent adenoidectomy for medication for CRS Previously, pediatrics table (4). Each of the incorporated investigations might have been doled out a level from claiming proof Also agrade about suggestion.

The opposite 127 articles were excluded Similarly as it didn't satisfy Incorporation criteria.

Table (1) Summary of screening of articles.

\begin{tabular}{lccc}
\hline Keywords & Number of articles & Relevant & Irrelevant \\
\hline $\begin{array}{l}\text { Medical treatment of chronic rhinosinusitis in } \\
\text { children. }\end{array}$ & 73 & 47 & 26 \\
$\begin{array}{l}\text { Pediatric chronic rhinosinusitis } \\
\text { Functional endoscopic sinus surgery in children }\end{array}$ & 57 & 37 & 20 \\
$\begin{array}{l}\text { Adenoidectomy for chronic rhinosinusitis in } \\
\text { children. }\end{array}$ & 94 & 31 & 63 \\
$\begin{array}{l}\text { Surgical treatment of chronic rhinosinusitis in } \\
\text { children. }\end{array}$ & 20 & 14 & 6 \\
Total & 95 & 54 & 41 \\
\hline
\end{tabular}

Table (2) Summary of articles results. 


\begin{tabular}{lc}
\hline & Number of articles \\
\hline Tolal & 339 \\
Irrelevant articles & 156 \\
Repeated articles & 41 \\
Relevant articles(142) & Excluded articles(127) \\
& Included articles (15) \\
\hline
\end{tabular}

Table (3) Summary of included articles

\begin{tabular}{|c|c|c|}
\hline $\begin{array}{l}\text { Number of the } \\
\text { article }\end{array}$ & Authors and date of the article & Article Title \\
\hline 1 & Chang et al, 2004 & $\begin{array}{l}\text { Functional endoscopic sinus surgery in } \\
\text { children using a limited approach (8) } \\
\text { FESS in the Paediatric Population: }\end{array}$ \\
\hline 2 & Fakhri et al, 2001 & $\begin{array}{c}\text { Outcome of a Conservative Approach to } \\
\text { Postoperative Care (9) }\end{array}$ \\
\hline 3 & Hebert and Bent, 1998 & $\begin{array}{l}\text { Meta-analysis of outcomes of pediatric } \\
\text { functional andoscopic sinus surgery (10) }\end{array}$ \\
\hline 4 & Jiang and Hsu, 2000 & $\begin{array}{l}\text { Functional Endoscopic Sinus Surgery in } \\
\text { Children and Adults (11) }\end{array}$ \\
\hline 5 & Ramadan, 2004 & $\begin{array}{c}\text { Surgical management of chronic sinusitis } \\
\text { in children (14) }\end{array}$ \\
\hline 6 & Ramadan and Cost, 2008 & $\begin{array}{l}\text { Outcome of adenoidectomy versus } \\
\text { adenoidectomy with maxillary sinus wash } \\
\text { for chronic rhinosinusitis in children.(12) }\end{array}$ \\
\hline 7 & Ramadan and Tiu, 2007 & $\begin{array}{l}\text { Failures of adenoidectomy for chronic } \\
\text { rhinosinusitis in children: for whom and } \\
\text { when do they fail (13) }\end{array}$ \\
\hline 8 & Rosenfeld, 1995 & $\begin{array}{l}\text { Pilot study of outcomes in pediatric } \\
\text { rhinosinusitis (15) }\end{array}$ \\
\hline 9 & Takahashi, 1989 & Effects of adenoidectomy on sinusitis (16) \\
\hline 10 & Tuncer et al, 2004 & $\begin{array}{l}\text { Chronic rhinosinusitis and adenoid } \\
\text { hypertrophy in children (17) }\end{array}$ \\
\hline 11 & Vandenberg, 1997 & $\begin{array}{c}\text { Efficacy of adenoidectomy in relieving } \\
\text { symptoms of chronic sinusitis in } \\
\text { children }(18)\end{array}$ \\
\hline 12 & Valstarkos et al , 2013 & $\begin{array}{c}\text { FESS Improves Sinus-Related Symptoms } \\
\text { and QualityofLife in Children With } \\
\text { ChronicRhinosinusitis }(20)\end{array}$ \\
\hline 13 & Makary and Ramadan, 2013 & The role of sinus surgery in children (21) \\
\hline 14 & Elsharkawy et al, 2012 & $\begin{array}{c}\text { FESS in children: predictive factors of } \\
\text { outcome (22) }\end{array}$ \\
\hline 15 & Taylor et al, 2014 & $\begin{array}{c}\text { comprehensive quality of life outcomes for } \\
\text { pediatric patients undergoing endoscopic } \\
\text { sinus surgery (19) }\end{array}$ \\
\hline
\end{tabular}

\section{Outcome Assessment}

Pooling Of The Results From The Included Articles

Adenoidectomy Yielded The Following Results: For Both FESS And

Table (4) Total no. of patients and no. of patients who didn't improve for the adenoidectomy group.

\begin{tabular}{lccc}
\hline Authors and year & $\begin{array}{c}\text { Total no. of } \\
\text { patients }\end{array}$ & $\begin{array}{c}\text { No. of patients } \\
\text { who improved }\end{array}$ & $\begin{array}{c}\text { No. of patients who didn't } \\
\text { improve }\end{array}$ \\
\hline Rosenfeld, 1995 & 8 & $6(75 \%)$ & $2(25 \%)$ \\
Takahashi, 1989 & 45 & $25(55.5 \%)$ & $20(44.6 \%)$ \\
Vandenberg, 1997 & 44 & $35(79.5 \%)$ & $9(20.5 \%)$ \\
Tuncer et al, 2004 & 27 & $22(81.4 \%)$ & $5(18.6 \%)$ \\
Table (4) Continue & & & \\
\hline
\end{tabular}




\begin{tabular}{lccc}
\hline Ramadan and Tiu, 2007 & 121 & $60(49.5 \%)$ & $61(50.5 \%)$ \\
Ramadan and cost, 2007 & 28 & $17(60.7 \%)$ & $11(39.3 \%)$ \\
Total & 273 & $165(60.4 \%)$ & $108(39.6 \%)$ \\
\hline
\end{tabular}

Table (5) Total no. of patients and no. of patients who didn't improve for the FESS group.

\begin{tabular}{lccc}
\hline Authors and year & $\begin{array}{c}\text { Total no. of } \\
\text { patients }\end{array}$ & $\begin{array}{c}\text { No. of patients who } \\
\text { improved }\end{array}$ & $\begin{array}{c}\text { No. of patients who } \\
\text { didn't improve }\end{array}$ \\
\hline Hebert and Bent, 1998 & 882 & $782(88.7 \%)$ & $100(11.3)$ \\
Jiang and Hsu, 2000 & 22 & $17(77.3 \%)$ & $5(12.7 \%)$ \\
Fakhri et al, 2001 & 19 & $15(79 \%)$ & $4(21 \%)$ \\
Ramadan, 2004 & 40 & $30(75 \%)$ & $10(25 \%)$ \\
Chang et al, 2004 & 101 & $87(86 \%)$ & $14(14 \%)$ \\
Valstarkos et al, 2013 & 1301 & $1112(85.5 \%)$ & $188(14.5 \%)$ \\
Taylor et al, 2014 & 22 & $19(85 \%)$ & $3(15 \%)$ \\
Elsharkawy et al, 2012 & 87 & $76(87.7 \%)$ & $11(12.3 \%)$ \\
Makary and Ramadan, & 634 & $577(91 \%)$ & $57(9 \%)$ \\
$\mathbf{2 0 1 3}$ & & & \\
Total & 3108 & $2715(87.4 \%)$ & $393(12.6 \%)$ \\
\hline
\end{tabular}

\section{Data Analysis And Interpretation}

Our study analyzed 15 articles studying pediatrics patients in which 3108 patients underwent endoscopic sinus surgery and 273 patients underwent adenoidectomy for treatment of CRS Table (3). Were 394 (12.6\%) of the
3108 patients who underwent endoscopic sinus surgery showed no improvement as regarding symptoms and signs of chronic rhinosinusitis Table( 5), while 108 $(39.1 \%)$ of the 273 patients who underwent adenoidectomy showed no improvement Table (8).

Table (8) Summary of results .

\begin{tabular}{lccc}
\hline & Total & Improvement & No improvement \\
\hline Patients who underwent adenoidectomy & 273 & $165(60.4 \%)$ & $108(39.6 \%)$ \\
Patients who underwent FESS & 3108 & $2715(87.4 \%)$ & 393 \\
\hline
\end{tabular}

\section{Conclusion}

We have on debilitate every last bit Also each method for diagnosis, prevention, What's more medicinal help in front of enthralling At whatever surgical intercession. Adenoidectomy appears on a chance to be the introductory sensible methodology from claiming decision.

This is a greater amount advocated to more youthful age class Youngsters. Maxillary wash might be of quality over patients with helter skelter ct score.

Fess remains the surgical methodology of decision to those extreme medicine of pediatric sinusitis At whatever point All that else neglects. It will be also sheltered with low occurrence of difficulties might have been watched with this kind from claiming medication.

\section{References}

[1] W.Michael, Ciddle, S.Amy, S.Mohmmedi andC.James, Pediatric chronic sinusitis: a retrospective review, American J.,

Otolaryngology-Head and Neck medicine and Surgery, Vol.29, PP.372-378, 2008.

[2] S.Kwang, H.Seok, R.Kyung T.Kyung, H.Seung,W.Chul andH.Jin, the role of adenoids in pediatric rhinosinsuitis. International J.,Pediatric
[3] Otorhinolaryngeology, Vol.72, PP.1643- 1650, 2008.

[4] E.John, Pediatric Sinusitis, Surgical Treatment. International J.,Pediatric Otorhinolaryngeology, Vol.25, PP.1-32, 2008.

[5] H.Takahashi,I.Honjo, A.Fujita and K.Kurata, Effects of adenoidectomy on sinusitis. Acta Oto-RhinoLaryngol Belgica, Vol.51 (2), PP.85-87, 1997.

[6] N.Dkk , P.Chow,L.Lck, K.Chau, E.ChanandH.Jcs, Randmized controlled trial of azithromycin and amoxicillin clavulinic in management of subacute childhood rhinosinsuitis. J. Paediatr. Child Health, Vol.36, PP.378-381, 2000.

[7] G.Felisati and H.Ramadan, Rhinosinsuitis in children: The role of surgery. Pediatric Allergy Immunol, Vol.18,pp .68-70,2007.

[8] S.Kwang, H.Seok, R.KyungT.Kyung, H.Seung,W.Chul andH.Jin, the role of adenoids in pediatric rhinosinsuitis. International J.,Pediatric Otorhinolaryngeology , Vol.72, PP.1643- 1650, 2008.

[9] P.Chang, L.Lee, C.Huang, C.Lai andT.Lee, Functional endoscopic sinus surgery in children using a limited approach. Arch Otolaryngol Head Neck Surg, Vol.130 (9), PP.1033-1036, 2004.

[10] S.Fakhri, J.John, J.Manoitkian, and J.Souaid,Functional Endoscopic Sinus Surgery in the Paediatric Population: Outcome of a 
Conservative Approach to Postoperative Care.The J.,Otolaryngology, Vol.30, PP.15-18, 2001.

[11]R.Herbert andJ.Bent,Meta-analysis of outcomes of pediatric functional andoscopic sinus surgery. Laryngoscope, Vol.108 (6), PP.796-799, 1998.

[12]R.Jiang and C.Hsu, Functional Endoscopic Sinus Surgery in Children and Adults . Ann Otol Rhinol Laryngol;Vol. 109(12), PP.1112-1116, 2000.

[13] H.Ramadan andJ.Cost ,Outcome of adenoidectomy versus adenoidectomy with maxillary sinus wash for chronic rhinosinusitis in children. Laryngoscope, Vol. 118 (5), pp .871-3, 2008.

[14] H.Ramadan and J.Tiu, Failures of adenoidectomy for chronic rhinosinusitis in children: for whom and when do they fail, Laryngoscope , Vol.117, PP.1080-1083, 2007.

[15]H.Ramadan,Surgical management of chronic sinusitis in children, Laryngoscope, Vol.114, pp $.2103-2109,2004$.

[16]R.Rosenfeld , Pilot study of outcomes in pediatric rhinosinusitis, Arch. Otolaryngol. Head Neck Surg, Vol.121 PP. 729-736, 1995.

[17] H.Takahashi,I.Honjo, A.Fujita and K.Kurata,Effects of adenoidectomy on sinusitis. Acta Oto-RhinoLaryngol Belgica, Vol. 51(2) PP.85-87, 1997.

[18] U.Tuncer, B.Aydogan, L.Soylu,M.Simsek,C.Ackali andA.Cucuckan, Chronic rhinosinusitis and adenoid hypertrophy in children, Am. J. Otolaryngol, Vol.25 (1) , PP.5-10, 2004.

[19] S.Vandenberg,D.G. Heatley, Efficacy of adenoidectomy in relieving symptoms of chronic sinusitis in children, Arch. Otolaryngol. Head Neck Surg, Vol.123, PP. 675-678, 1997.

[20] J.Robert,Taylor,D.Justin;comprehensive quality of life outcomes for pediatric patients undergoing endoscopic sinus surgery, Rhinology , Vol.52, PP.327-333, 2014.

[21] V.Petros. Vlastarakos, Melpomeni Fetta, V. John,Segas, Functional Endoscopic Sinus Surgery Improves Sinus-Related Symptoms and QualityofLife in Children With Chronic Rhinosinusitis, Clinical Pediatrics, Vol.52(12), PP.1091-1097, 2013.

[22] A. C. Makary, H.H.Ramadan; The role of sinus surgery in children. The American Laryngological,Rhinological and Otological Society, Inc: Layngoscope ;Vol.123,PP.1348-1352,2013.

[23]A.Asser,M.El Sharkawy, Shawky ,Elmorsy,M. Hesham Eladl, Functional endoscopic sinus surgery in children: predictive factors of outcome, Mansoura University, Mansoura, Egypt. Eur Arch Otorhinolaryngol , Vol.269, PP.107-111, 2012. 